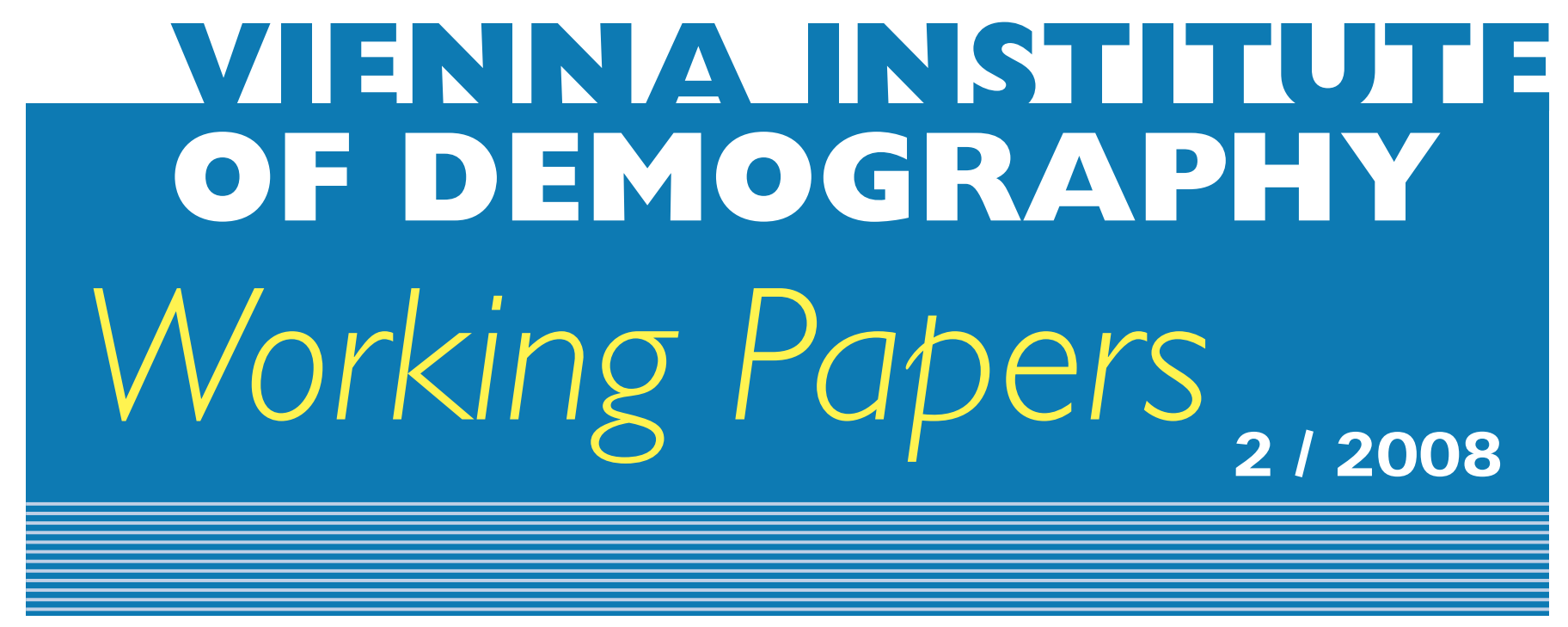

Franz Schwarz, Christian Korbel, and Johannes Klotz

\title{
Alcohol-related mortality among men in Austria 1981-2002 and the importance of qualification and employment
}

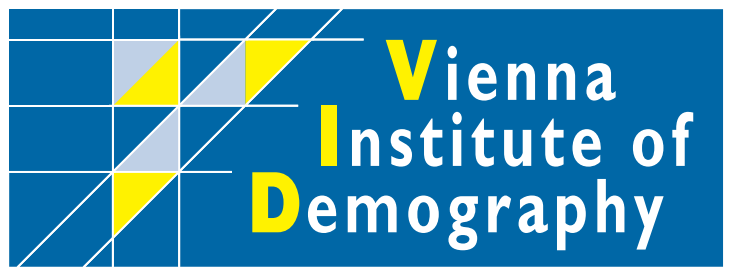

Vienna Institute of Demography Austrian Academy of Sciences

Wohllebengasse 12-14

A-I040Vienna $\cdot$ Austria

E-Mail:vid@oeaw.ac.at

Website: www.oeaw.ac.at/vid

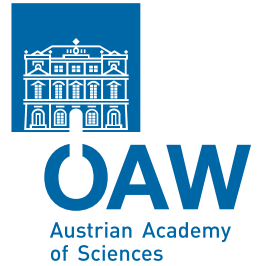




\begin{abstract}
The aim of this paper is to explore the relationship between alcohol-related mortality and social status among men in Austria, and to examine changes during the 1980s and 1990s. We linked individual census records for the Austrian population from 1981, 1991, and 2001 with death register records for a follow-up period of one year. The final data set contains 5,038,654 records of men 35-74 years old, of whom 3824 died of causes explicitly related to alcohol abuse. Standardized mortality ratios by education, occupation and employment were calculated for alcohol- and non-alcohol-related causes of death. A regression-based inequality measure was used for analyses of trends. We find that low educated men were 2.77 (1981/82), 3.49 (1991/92), and 3.23 (2001/02) times more likely to die of alcohol-related causes of death than high educated, while it was just 1.59, 1.80, and 1.89 for other conditions. Among men 35-59 years old, unskilled blue-collar workers had on average a 5.6 and 5.0 times higher risk than upper white-collar employees in 1981/82 and 1991/92; for non-alcohol related causes it was 2.0 and 2.2. Unemployed or early retired men were particularly at risk. In 2001/02 low-skilled inactive were 18 times more likely to die on alcohol-related causes than high-skilled economically active men. Over time the social inequalities in alcohol-related mortality increased but only between 1981/82 and 1991/92; and among those 35-59 years old only for the economically inactive. A good education and sophisticated vocational skills are important protective factors for alcohol problems; however, what matters most is whether or not people are employed.
\end{abstract}

\title{
Keywords
}

Alcoholism, addiction, mortality, employment, education, occupation

\section{Authors}

Franz Schwarz is a research scientist at the Vienna Institute of Demography of the Austrian Academy of Sciences. Email: Franz.Schwarz@oeaw.ac.at

Christian Korbel is a psychiatrist and psychotherapist, and the medical head of the psychosocial outreach clinic in Amstetten in Lower Austria.

Johannes Klotz is a demographer at Statistics Austria. 


\title{
Alcohol-related mortality among men in Austria 1981-2002 and the importance of qualification and employment
}

\author{
Franz Schwarz, Christian Korbel, and Johannes Klotz
}

\section{Introduction}

Alcoholism is a widespread disorder associated with significant co-morbidity and mortality in all social classes. The lower social classes, though, are more affected by heavy drinking than those at the higher end of the social scale. The magnitude of these disparities, however, is difficult to determine. Surveys on health and lifestyle occasionally include questions on alcohol consumption but results from these studies have to be treated with caution. Respondents who abuse alcohol may under-report their consumption out of embarrassment, or they do not respond to the question at all. Moreover, alcoholics tend not to participate in face-to-face surveys. The present study makes a valuable contribution to the research on social disparities in alcoholism by examining disparities in alcohol-related causes of death using exclusive data of the entire Austrian population 1981, 1991, and 2001, each followed up for one year of mortality.

Recent Austrian studies on cause-specific mortality differentials by education have already found large educational disparities in alcohol-associated mortality (Schwarz 2007), with increasing disparities between 1981 and 1991 (Schwarz 2006). We extend this research by taking a closer look at the alcohol-related mortality differentials using education, occupation class and employment status as indicators of social stratification. Special attention is given to the differences in mortality between the economically active people and those who were early retired or unemployed. We also examine whether or not alcohol-related mortality differentials increased during the 1980s and the 1990s.

In addition, mortality disparities among those who died of diseases related to alcohol abuse are compared to differentials of those who died from other conditions in order to show the seriousness of social disparities in alcohol abuse. We assume that the magnitude of the social differentials for alcohol-related mortality is much higher than it is for deaths from other causes.

There are generally four levels of alcohol drinking: social drinking, heavy drinking, problem (harmful) drinking without being dependent on alcohol, and dependence (addiction). Each level increases the risk to health and safety (Ashworth and Gerada 1997). This paper primarily comprises alcohol addicts and problem drinkers, as the causes of death examined here are explicitly related to alcohol abuse. At this drinking level, consumption causes serious problems or harms to drinkers, their family and social network, or to society.

Monitoring alcohol-related mortality disparities is an important public health task because it can provide vital information for health policies and measures that may reduce such inequalities, improve the health of the population, and contain health care costs. 


\section{Data and Methods}

The estimates of this study are based on individual-level census records of the entire Austrian population from 1981, 1991, and 2001 that were linked with the death registry for a follow-up period of one year. The linkage success for the study population of men 35-74 years old was around $93 \%$ and differs by follow-up period, region, and sexes. The record linkage approach for 1981 and 1991 has been described by Doblhammer et al. (2005), and for 2001 by Klotz (2007). Altogether, our final data set contains 5,038,654 individual records. According to these records, 54,492 people died within the 1-year observation period, of whom 3824 died of alcohol-related causes as defined in this study. The percentages of population and deaths in each follow-up period are shown in Table 1 . We examine the following indicators of social stratification: educational attainment, occupation, employment status, and the combination of employment status and education. Occupation is based on present occupation for those who are economically active and on former occupation for those who are unemployed or retired.

The causes of death were classified according to the International Classification of Diseases, 9th Revision (ICD-9) for 1981/82, 1991/92, and 2001, and according to ICD-10 for deaths in 2002. The alcohol-related causes of death explored in this study are listed in Table 1. Liver disease is the main alcohol-related cause of death. However, deaths from alcoholic-caused liver disease are seriously underreported; such deaths are often attributed to cirrhosis of the liver without mentioning alcohol (Smith 1993). Thus, we allocated deaths from liver cirrhosis without mentioning alcohol to alcohol-related causes, even though we include a certain percentage incorrectly. Deaths from pancreatic diseases were also allocated to alcohol-related causes of death since Zilker et al. (2004) suggest that in $40-95 \%$ of the cases, pancreatitis is caused by chronic alcohol abuse. Hence, alcoholrelated deaths according to ICD-9 will be over-reported while the number of deaths according to ICD-10 may be more accurately reported, as here there is an explicit diagnosis for alcohol-induced pancreatitis.

We calculated age-standardized mortality ratios (SMRs) by social class, based upon 5-year age groups, using the age-specific death rates of the total population as standard. Confidence intervals for the SMRs were calculated on the assumption that the observed deaths follow a Poisson distribution (Ulm 1990). For trend analyses of educational inequalities the Relative Index of Inequality (RII) was applied. The RII is obtained by arranging the education groups from lowest to highest reflecting the cumulative proportionate distribution of the population. As a result, each group covers a range proportional to its population size. The midpoint of the range covered by that group is used as values reflecting the educational categories. Subsequently, the RII was calculated through logistic regression with the education and age group as independent variables. The exponential of the regression coefficient for the variable education results in the RII. In this respect, the RII can be interpreted as the odds ratio between the hypothetically least educated and most highly educated, with education ranging from zero to one. The RII takes the relative position of the educational groups into account, which is an advantageous property to account for changes in the education distribution over time. A detailed specification of the RII, along with calculation of confidence intervals, can be found in Hayes and Berry (2002). In all analyses, two-sided 95\% confidence intervals are used. 
Calculations were carried out with the $R$ Language and Environment for Statistical Computing and Graphics, Version 2.4.1.

Table 1: Percentage of population and alcohol-related deaths by qualification and employment status for men 35-74 years old, Austria, follow up periods 1981/82, 1991/92 and 2001/02

\begin{tabular}{|c|c|c|c|c|c|c|}
\hline & \multicolumn{3}{|c|}{ Alcohol-related deaths } & \multicolumn{3}{|c|}{ Population } \\
\hline & $1981 / 82$ & $1991 / 92$ & $2001 / 02$ & $1981 / 82$ & $1991 / 92$ & $2001 / 02$ \\
\hline & \multicolumn{6}{|c|}{ Ages 35-74 year } \\
\hline \multicolumn{7}{|l|}{ Education } \\
\hline $\operatorname{High}^{[a]}$ & 5.2 & 5.7 & 7.4 & 12.8 & 15.8 & 19.5 \\
\hline Middle $^{[\mathrm{b}]}$ & 44.3 & 48.2 & 57.0 & 47.8 & 53.9 & 59.4 \\
\hline $\operatorname{Low}^{[\mathrm{c}]}$ & 50.5 & 46.1 & 35.6 & 39.4 & 30.3 & 21.2 \\
\hline \multicolumn{7}{|l|}{ Occupation } \\
\hline Upper white collar ${ }^{[\mathrm{d}]}$ & 3.3 & 4.9 & $\mathrm{n} / \mathrm{a}$ & 10.1 & 12.6 & $\mathrm{n} / \mathrm{a}$ \\
\hline Middle white collar ${ }^{[\mathrm{e}]}$ & 11.9 & 16.6 & $\mathrm{n} / \mathrm{a}$ & 20.8 & 23.6 & $\mathrm{n} / \mathrm{a}$ \\
\hline Lower white collar & 8.2 & 7.8 & $\mathrm{n} / \mathrm{a}$ & 9.0 & 7.2 & $\mathrm{n} / \mathrm{a}$ \\
\hline Skilled blue collar & 15.5 & 19.0 & $\mathrm{n} / \mathrm{a}$ & 15.6 & 18.1 & $\mathrm{n} / \mathrm{a}$ \\
\hline Semi-skilled blue collar ${ }^{[\mathrm{f}]}$ & 15.4 & 17.4 & $\mathrm{n} / \mathrm{a}$ & 12.4 & 12.7 & $\mathrm{n} / \mathrm{a}$ \\
\hline Unskilled blue collar & 18.2 & 18.2 & $\mathrm{n} / \mathrm{a}$ & 9.3 & 8.5 & $\mathrm{n} / \mathrm{a}$ \\
\hline Farmers ${ }^{[\mathrm{g}]}$ & 9.0 & 6.3 & $\mathrm{n} / \mathrm{a}$ & 10.0 & 9.2 & $\mathrm{n} / \mathrm{a}$ \\
\hline Self employed ${ }^{[\mathrm{h}]}$ & 8.0 & 6.3 & $\mathrm{n} / \mathrm{a}$ & 8.5 & 6.4 & $\mathrm{n} / \mathrm{a}$ \\
\hline Other ${ }^{[\mathrm{i}]}$ & 10.7 & 3.5 & $\mathrm{n} / \mathrm{a}$ & 4.4 & 1.6 & $\mathrm{n} / \mathrm{a}$ \\
\hline Number & 1,281 & 1,423 & 1,120 & $1,487,847$ & $1,626,915$ & $1,923,892$ \\
\hline \multicolumn{7}{|c|}{ Working population ages $35-59$ years } \\
\hline \multicolumn{7}{|l|}{ Employment status } \\
\hline Employed & 44.0 & 31.7 & 26.8 & 90.8 & 85.3 & 84.1 \\
\hline Unemployed & 10.7 & 15.1 & 21.6 & 2.1 & 4.5 & 5.7 \\
\hline Early retired & 43.4 & 48.5 & 45.4 & 6.3 & 8.4 & 8.1 \\
\hline Other ${ }^{[i]}$ & 2.0 & 4.7 & 6.1 & 0.8 & 1.8 & 2.0 \\
\hline \multicolumn{7}{|c|}{ Employment status ${ }^{[j]} \&$ education } \\
\hline Active high skilled & 2.8 & 3.1 & 4.0 & 12.5 & 15.4 & 19.7 \\
\hline Active mid skilled & 19.9 & 18.9 & 17.9 & 46.2 & 49.3 & 52.3 \\
\hline Active low skilled & 21.2 & 9.7 & 4.9 & 32.1 & 20.6 & 12.1 \\
\hline Inactive high skilled & 2.5 & 1.8 & 4.4 & 0.6 & 1.0 & 1.9 \\
\hline Inactive mid skilled & 23.3 & 33.4 & 45.6 & 3.6 & 7.1 & 9.3 \\
\hline Inactive low skilled & 30.2 & 33.1 & 23.2 & 5.0 & 6.5 & 4.7 \\
\hline Number & 712 & 829 & 570 & $1,099,890$ & $1,200,344$ & $1,413,664$ \\
\hline
\end{tabular}

[a] Secondary school diploma qualifying for university admission, college, university

[b] Apprenticeship or vocational school

[c] Compulsory education

[d] With high education

[e] With middle education

[f] No professional education but received some practical training

[g] Income mainly from farming or foresting

[h] Income mainly from their own business regardless of company size or number of employees

[i] Other source of income (from parents or other supporter, own funds, state assistance), home maker, or unknown

[j] Economically active are those employed; unemployed, early retired and "other" are combined in the category economically inactive 
Table 2: Alcohol-related causes of death according to ICD-10 and ICD-9, and number of deaths among men in Austria 35-74 years old

\begin{tabular}{|c|c|c|c|c|c|c|}
\hline \multirow{2}{*}{ ICD-10 } & \multirow{2}{*}{\multicolumn{3}{|c|}{ ICD-9 }} & \multicolumn{3}{|c|}{ Number of deaths } \\
\hline & & & & $1981 / 82$ & 1991/92 & $2001 / 02$ \\
\hline \multirow{3}{*}{$\begin{array}{l}\text { Mental and behavioral disorders due } \\
\text { to use of alcohol }\end{array}$} & \multirow[t]{3}{*}{ F10 } & Alcohol-induced mental disorders & 291 & \multirow{3}{*}{68} & \multirow{3}{*}{172} & \multirow{3}{*}{224} \\
\hline & & Alcohol dependence syndrome & 303 & & & \\
\hline & & Alcohol abuse & 305.0 & & & \\
\hline Alcoholic polyneuropathy & G62.1 & Alcoholic polyneuropathy & 357.5 & 1 & 0 & 1 \\
\hline Alcoholic cardiomyopathy & I42.6 & Alcoholic cardiomyopathy & 425.5 & 0 & 0 & 11 \\
\hline Alcoholic gastritis & K29.2 & Alcoholic gastritis & 535.3 & 1 & 0 & 0 \\
\hline \multirow[t]{4}{*}{ Alcoholic liver disease } & K70 & Alcoholic fatty liver & 571.0 & \multirow{4}{*}{110} & \multirow{4}{*}{121} & \multirow{4}{*}{169} \\
\hline & & Acute alcoholic hepatitis & 571.1 & & & \\
\hline & & Alcoholic cirrhosis of liver & 571.2 & & & \\
\hline & & Alcoholic liver damage, unspecified & 571.3 & & & \\
\hline Hepatic fibrosis & K74.0 & \multirow{4}{*}{$\begin{array}{l}\text { Cirrhosis of liver without mention of } \\
\text { alcohol }\end{array}$} & \multirow[t]{4}{*}{571.5} & \multirow{4}{*}{1005} & \multirow{4}{*}{1047} & \multirow{4}{*}{744} \\
\hline Hepatic sclerosis & K74.1 & & & & & \\
\hline $\begin{array}{l}\text { Hepatic fibrosis with hepatic } \\
\text { sclerosis }\end{array}$ & K74.2 & & & & & \\
\hline $\begin{array}{l}\text { Other and unspecified cirrhosis of } \\
\text { liver }\end{array}$ & K74.6 & & & & & \\
\hline Alcohol-induced acute pancreatitis & K85.2 & Diseases of pancreas & 577 & 96 & 83 & 40 \\
\hline Alcohol-induced chronic pancreatitis & K86.0 & & & & & \\
\hline
\end{tabular}

\section{Results}

Age standardized mortality ratios (SMR) by period and social stratification for alcoholrelated mortality (left side of the table) and for other condition than alcohol-related (right side of the table) are shown Table 3. An SMR for alcohol-related diseases of 139 among low-educated men in 2001/02 means that there were 39\% more deaths from alcohol-related diseases in this group than in the national population. Contrary, an SMR of 43 for the higher-educated men indicates a 67\% lower alcohol-related mortality in this group compared to the total population. In this respect, the SMR points out the magnitude of protection that belonging to a certain group has in comparison to the national population. Apparently, belonging to a higher class is a protective factor while the affiliation with a lower social group ends in a higher mortality, regardless of which variable was chosen as indicator for social stratification: education, occupation or employment.

For mortality related to alcohol abuse the SMRs increased much more with decreasing social status than for non-alcohol related causes of death. Depending on the social indicator and period, the magnitude of the social differentials for alcohol-related mortality was around two to three times higher than it was for deaths from other causes. For instance, among men 35-74 years old the low-versus-high education ratio for alcoholrelated mortality was 2.77 for $1981 / 82,3.49$ for $1991 / 92$, and 3.23 for $2001 / 02$, while they were just $1.59,1.80$, and 1.89 for other causes of death. Rate ratios are not shown in Table 3 , but they can easily be calculated by dividing the SDR of a particular group by the SDR of a reference group. Even higher disparities were observed with regard to occupation. Unskilled blue-collar workers had on average a 5.6 and 5.0 times higher probability of 
dying than upper white-collar employees in 1981/82 and 1991/92, while it was just 2.0 and 2.2 for other causes of death.

Table 3: Age standardized mortality ratios (SMRs) by qualification and employment status for males, alcohol-related mortality and mortality for other causes of death than alcoholrelated, 1981/82, 1991/92, and 2001/02 (95\% CI in parenthesis)

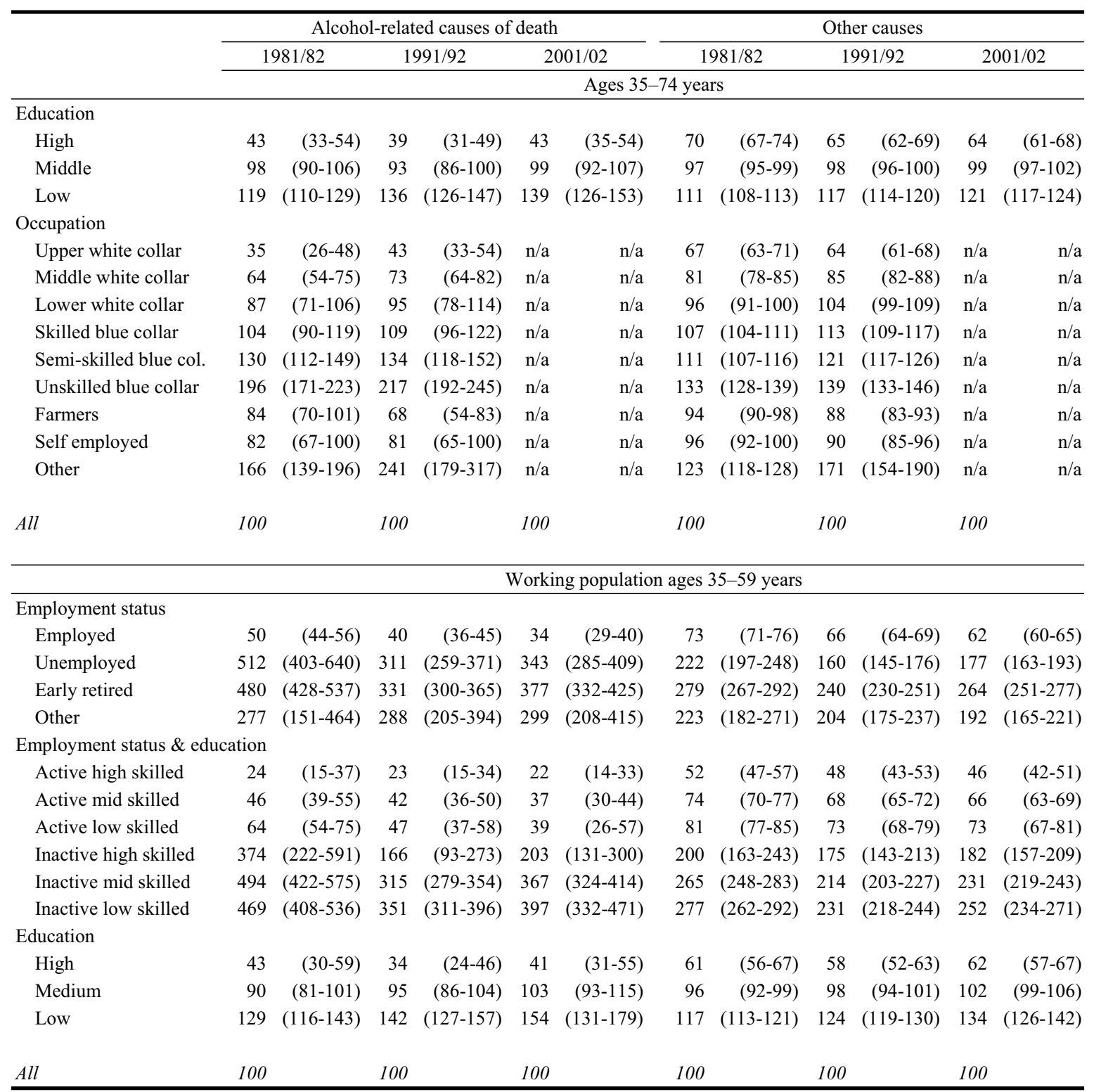

Among the working population ages 35-59 years those who were economically inactive were highly at risk of dying from an alcohol-related cause. Among unemployed and early retired men, the risk of an alcohol-related death was around ten times higher than it was for employed men. The largest inequalities, however, were observed for the combination of employment status and education: In 2001/02 the risk for dying from an alcohol-related disease was staggering: 18 times higher for low-skilled inactive people compared to high- 
skilled active employees, while it was 5.5 times higher with regard to non-alcohol-related causes of death.

Figure 1: Age-specific mortality rates (per 100.000 person-years) and rate ratios for alcohol-related causes of death by education, occupation, and employment status, Austria, follow-up periods 1981/82, 1991/92 and 2001/02 pooled

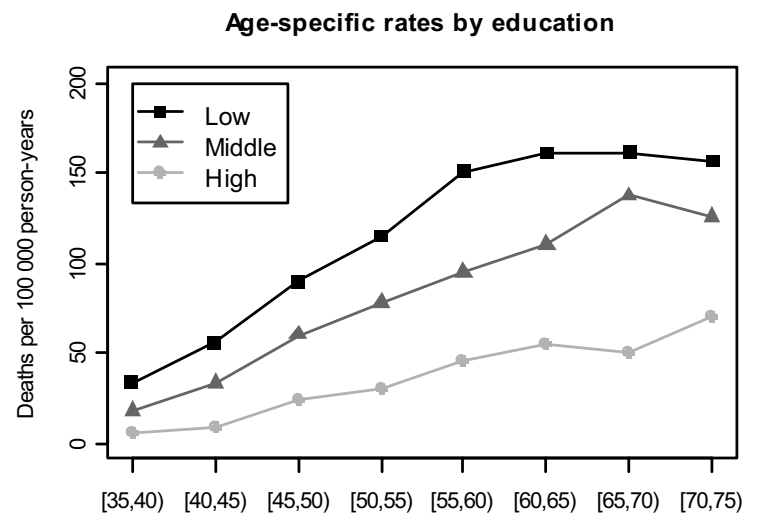

Age

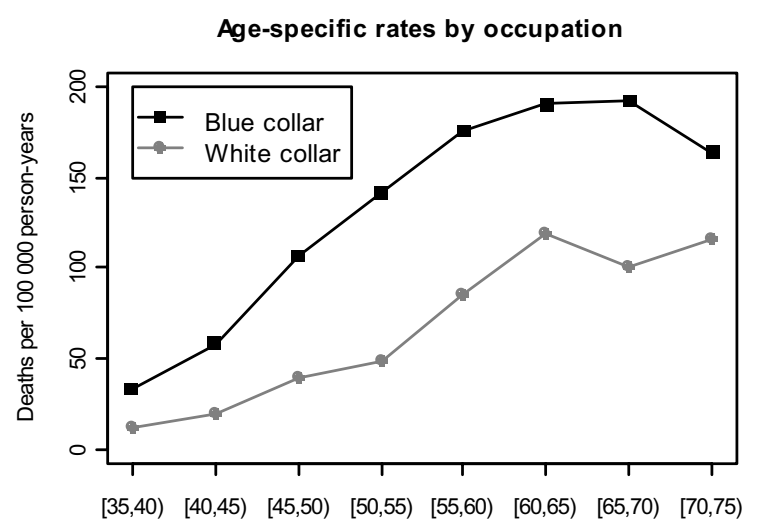

Age

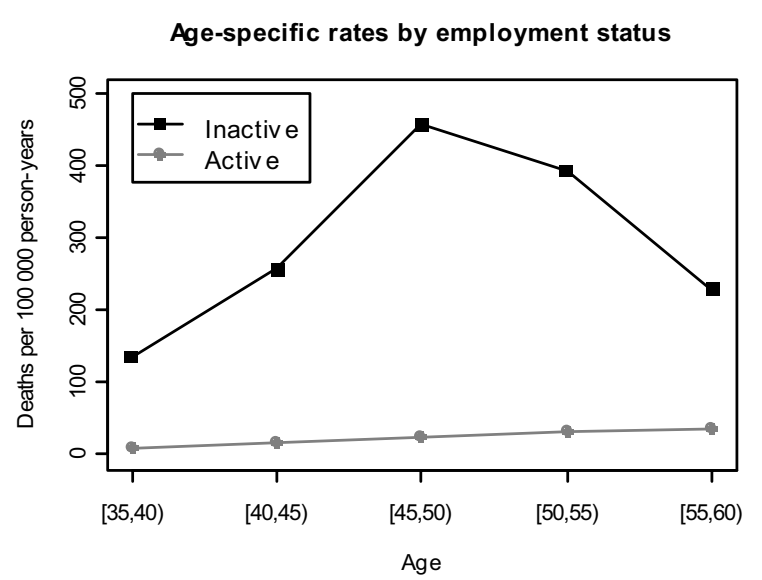

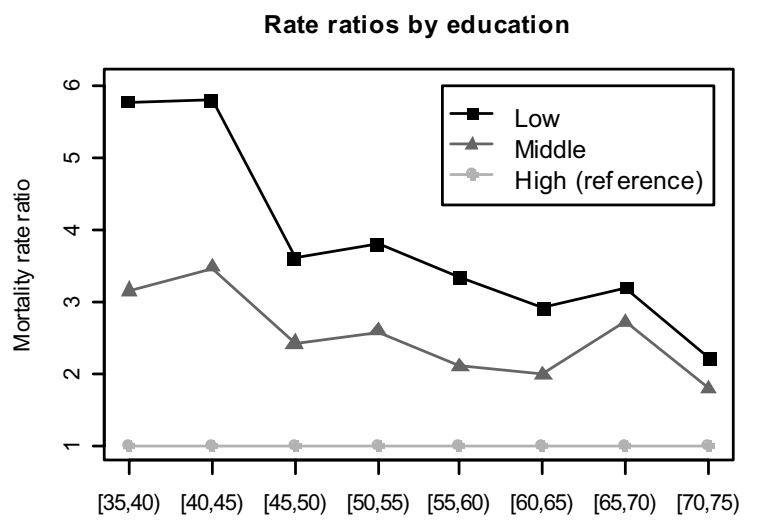

Age

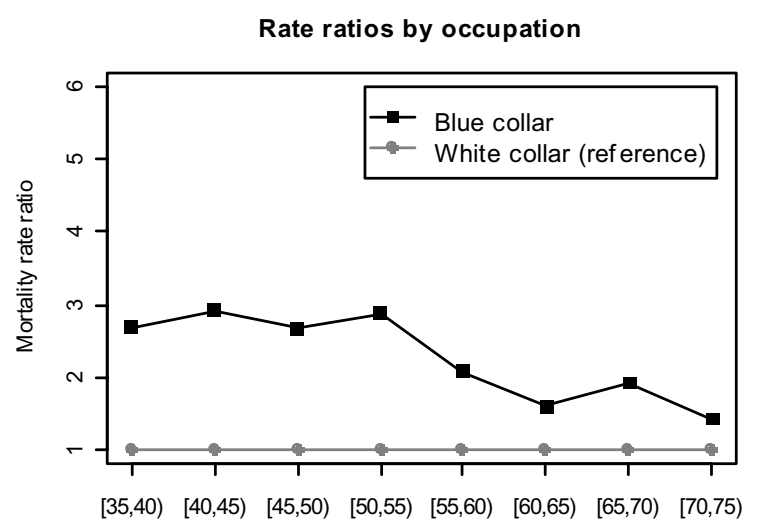

Age

Rate ratios by employment status

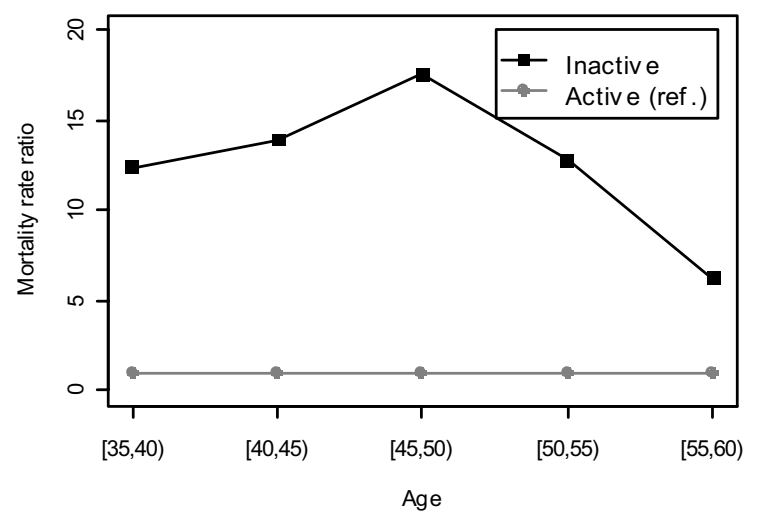


The age-specific mortality rates and rate ratios in Figure 1 show declining disparities in alcohol-related mortality with age across educational groups and occupational classes. Disparities between active and inactive people, however, increase until middle age and then decline.

The Relative Index of Inequality in Table 4 describes educational disparities in terms of the odds ratio between the hypothetical lowest and highest education group. Increasing educational inequalities in alcohol-related mortality can only be observed between 1981/82 and 1991/92. However, among the economically active people, disparities declined between these two periods. In contrast, among the economically inactive there was no education-specific inequality in 1981/82 but the disparity increased to an RII of 1.7 one decade later.

The findings for all 35-59 year olds show a vast increase in alcohol-related mortality disparities that is mainly a result of changes in the population composition. In 1991/92 more people were economically inactive than ten years before, and as employment is such an influencing factor, disparities for both the active and inactive groups together increased so much, despite the decline in disparity among the economically active. The same applied to other causes than alcohol-related, but here almost no change occurred for both economically active and inactive men.

Table 4: Relative Index of Inequality for economically active and inactive men, Austria, follow up periods 1981/82, 1991/92, and 2001/02

\begin{tabular}{|c|c|c|c|c|c|c|c|c|c|c|c|c|}
\hline \multirow[t]{3}{*}{ Population } & \multicolumn{12}{|c|}{ Relative Index of Inequality } \\
\hline & \multicolumn{6}{|c|}{ Alcohol-related causes of death } & \multicolumn{6}{|c|}{ Other causes } \\
\hline & \multicolumn{2}{|c|}{$1981 / 82$} & \multicolumn{2}{|c|}{$1991 / 92$} & \multicolumn{2}{|c|}{$2001 / 02$} & \multicolumn{2}{|c|}{$1981 / 82$} & \multicolumn{2}{|c|}{$1991 / 92$} & \multicolumn{2}{|c|}{$2001 / 02$} \\
\hline \multicolumn{13}{|l|}{$35-59$ years old } \\
\hline Active & 2.8 & $(1.8-4.4)$ & 2.1 & $(1.3-3.4)$ & 2.1 & $(1.1-3.9)$ & 1.6 & $(1.4-1.7)$ & 1.6 & $(1.4-1.9)$ & 1.8 & $(1.5-2.1)$ \\
\hline Inactive & 1.0 & $(0.6-1.4)$ & 1.7 & $(1.2-2.4)$ & 1.7 & $(1.1-2.5)$ & 1.2 & $(1.0-1.4)$ & 1.3 & $(1.1-1.6)$ & 1.4 & $(1.2-1.6)$ \\
\hline All & 3.0 & $(2.2-4.0)$ & 3.9 & $(3.0-5.2)$ & 4.2 & $(3.0-5.8)$ & 1.9 & $(1.8-2.1)$ & 2.3 & $(2.0-2.5)$ & 2.5 & $(2.2-2.8)$ \\
\hline $60-74$ years old & 1.7 & $(1.2-2.3)$ & 3.0 & $(2.2-4.0)$ & 2.9 & $(2.1-4.1)$ & 1.4 & $(1.3-1.5)$ & 1.7 & $(1.6-1.9)$ & 1.9 & $(1.7-2.0)$ \\
\hline 35-74 years old & 2.3 & $(1.9-2.9)$ & 3.5 & $(2.8-4.3)$ & 3.5 & $(2.7-4.4)$ & 1.6 & $(1.5-1.7)$ & 1.9 & $(1.8-2.0)$ & 2.1 & $(1.9-2.2)$ \\
\hline
\end{tabular}

\section{Discussion}

\subsection{Principal findings}

The striking results of this study show the importance of a good education and sophisticated vocational skills with regard to problem drinking. The higher the education and the more sophisticated the vocational skills are, the less likely people were to die of an alcohol-related cause. However, what matters most is whether or not people are employed. 
Comparing alcohol-related deaths with all other causes shows that the magnitude of alcohol-related mortality disparities was around two to three times higher than those for non-alcohol related causes - depending on the social indicator and on the period.

Over time, the social inequalities in alcohol-related mortality increased but only between 1981/82 and 1991/92 and only among the economically inactive men ages 35-59. Among economically active there was even a decline in alcohol-related mortality disparities between 1981/82 and 1991/92.

Age also played a very important role. With increasing age, disparities declined across educational groups and occupational classes. With regard to employment, disparities between active and inactive persons increased up to middle age and declined afterwards. A systematic selection of robust individuals was most likely the reason for the diminishing differentials with age.

\subsection{Our findings related to other studies}

Our findings are consistent with those of another Austrian study and with international findings. Uhl and Springer (Uhl and Springer 1996) showed that in Austria the proportion of college graduates decreased continuously with increasing alcohol consumption, leading to the conclusion that problem drinking is more frequent among the lower educated groups. With regard to alcohol-related deaths, findings from Sweden (Hemstrom 2002), Finland (Makela et al. 1997, Makela 1999, Pensola and Valkonen 2000, Valkonen et al. 2000, Martikainen et al. 2001, Herttua et al. 2007), and Russia (Shkolnikov et al. 1998, Bobak et al. 1999) report higher mortality among the lower socioeconomic classes. Further, a study from Scotland shows that in deprived areas problem drinking is more prevalent than elsewhere (Leyland et al. 2007).

\subsection{Policy and practice implications}

Because of the high incidence of alcohol abuse and the importance of education and employment comprehensive support in the forms of educational programs, career advancement and health education for deprived people and alcoholics could not only considerably reduce the incidence of alcohol-related disease but also improve the health of the population. Such public health measures probably are less costly than the treatment of alcoholism and alcohol-related diseases.

Measures that lower the rates of alcohol-related mortality among the socially disadvantaged will also have a huge effect on life expectancy. According to Bühringer et al. (2000) excess mortality is 17 years among male and 20 years among female alcoholics. Uhl (2002) suggests that around $80 \%$ of the addicts are male, resulting in 18 potential lifeyears lost for both sexes. As around $10 \%$ of all deaths are attributed to alcohol addiction, life expectancy for the entire Austrian population is reduced by an average of 1.8 years (Uhl 2002). Hence, focusing on reducing the number of alcohol-related deaths would considerably increase life expectancy. 


\subsection{Strengths and limitations of the study}

Although the results of this analysis provide strong evidence for the role of education, occupation and employment when it comes to alcohol abuse, some caution must be exercised in interpreting these findings. Firstly, the cross-sectional design of the study does not allow any conclusion that there is a causal relationship between socioeconomic status and alcohol abuse. This circumstance is less relevant for education since it remains virtually constant throughout adulthood and is less influenced by health problems that develop during adulthood. However, with regard to employment, people can become unemployed or retire early because of problem drinking or other health problems, or they start drinking heavily as a result of unemployment or retirement. Our study does not measure the effect of problem drinking on unemployment or early retirement, nor does it measure alcohol abuse that follows the loss of employment. However, at this point, causality is less important since one can assume that those who reported being unemployed or early retired at the reference date of the population census belong to a particular highrisk marginal group. There may also be "regular" people who were between jobs and reported being unemployed at the reference date. If we could identify and exclude these people from the economically inactive, the inequalities between the economically active and those who are inactive would very likely be even higher.

Secondly, it should be borne in mind that random variation could influence changes in the educational distribution of deaths. Therefore, results for changes over time should be treated with caution. However, strengths of this study include coverage of the entire adult population of Austria with little discernable bias in successful linkage, and the determination of education from census records resulting in no numerator/denominator discrepancies.

The concept of substance-related deaths (SRD) plays a major role in public health and has been extensively discussed (Uhl 2002). As the present paper uses the least problematic concept that concentrates on substance related deaths in the narrowest sense (SRDNS), the number of deaths for alcohol-associated diseases is, without a doubt, seriously under-reported in this study. Uhl et al. (2001) conclude from their calculations for Austria that per annum around 8,000 of the people who die are alcoholics. Of these, around 6,000 are male. The present paper, however, reports on average around 1300 alcohol-related deaths per annum among men 35-74 years old. The association between alcohol abuse and major causes of death is most apparent in alcoholic cirrhosis of the liver and alcohol-related psychosis, but few organs remain undamaged by chronic alcohol abuse. Hence, causes of death that are related to alcohol are often attributed to other causes. Secondary disorders of chronic alcohol abuse include diseases of the digestive system, pancreas, liver, endocrine and metabolic systems, heart and blood, not to mention neurological disorders (Zilker 2004). Chronic alcohol abuse often is accompanied by alcoholic depression (Soyka 1999), which may be partly responsible for the large differentials in suicides. Furthermore, alcohol in the blood significantly increases the risk for accidents, which may explain a substantial proportion of the social differentials related to accidental deaths (Smith 1993). Ashword and Gerada (1997) suggest that alcohol consumption is associated with $80 \%$ of suicides, $50 \%$ of murders, $80 \%$ of deaths from fire, $40 \%$ of road traffic accidents, $30 \%$ of fatal road traffic accidents, and $15 \%$ of drowning. 
However, the attribution of alcohol-related deaths to other causes of death does not affect measurement of relative inequalities for alcohol-related mortality as long as the incorrect attribution, in relative terms, occurs equally often in all social groups.

\subsection{Unanswered questions and future research}

The present study does not measure the direct effect of intervention programs such as further education, on-the-job-training or occupational therapy among those addicted to alcohol, nor does it measure the preventative effect of such programs among deprived people. More research has to be done on this topic. However, the study indeed shows the importance of qualification and employment, and suggests that public health measures that concentrate on these two factors would be very effective.

\section{References}

Ashworth, M. and Gerada, C. 1997. ABC of mental health: Addiction and dependence-II: Alcohol. BMJ, 315(7104), pp. 358-360.

Bobak, M., McKee, M., Rose, R. and Marmot, M. 1999. Alcohol consumption in a national sample of the Russian population. Addiction, 94(6), pp. 857-866.

Bühringer, G., Augustin, R., Bergmann, E., Bloomfeld, K., Funk, W., Junge, B., Kraus, L., Merfert-Diete, C., Rumpf, H. J., Simon, R. and Töppich, J. 2000. Alkoholkonsum und alkoholbezogene Störungen in Deutschland, Baden-Baden: Nomos.

Doblhammer, G., Rau, R. and Kytir, J. 2005. Trends in educational and occupational differentials in all-cause mortality in Austria between 1981/82 and 1991/92. Wiener Klinische Wochenschrift, 117(13-14), pp. 468-479.

Hayes, L. J. and Berry, G. 2002. Sampling variability of the Kunst-Mackenbach relative index if inequality. Journal of Epidemiology and Community Health, 56, pp. 762765.

Hemstrom, O. 2002. Alcohol-related deaths contribute to socioeconomic differentials in mortality in Sweden. Eur J Public Health, 12(4), pp. 254-262.

Herttua, K., Makela, P. and Martikainen, P. 2007. Differential trends in alcohol-related mortality: a register-based follow-up study in Finland in 1987 2003. Alcohol, 42(5), pp. 456-464.

Klotz, J. 2007. Soziale Unterschiede in der Sterblichkeit; Bildungsspezifische Sterbetafeln 2001/2002. Statistische Nachrichten. Wien: Statistik Austria.

Leyland, A. H., Dundas, R., McLoone, P. and Boddy, F. A. 2007. Cause-specific inequalities in mortality in Scotland: two decades of change. A population-based study. BMC Public Health, 7(147), pp. 172.

Makela, P. 1999. Alcohol-related mortality as a function of socio-economic status. Addiction, 94(6), pp. 867-886.

Makela, P., Valkonen, T. and Martelin, T. 1997. Contribution of deaths related to alcohol use to socioeconomic variation in mortality: register based follow up study. $B M J$, 315(7102), pp. 211-216.

Martikainen, P., Valkonen, T. and Martelin, T. 2001. Change in male and female life expectancy by social class: decomposition by age and cause of death in Finland 1971-95. J Epidemiol Community Health, 55(7), pp. 494-499. 
Pensola, T. H. and Valkonen, T. 2000. Mortality differences by parental social class from childhood to adulthood. J Epidemiol Community Health, 54(7), pp. 525-529.

Schwarz, F. 2006. The contributions of diseases to increasing educational mortality differentials in Austria. VID Working Paper 02/2006. Vienna: Vienna Institute of Demography, Austrian Academy of Sciences.

Schwarz, F. 2007. Causes of death contributing to educational mortality disparities in Austria. Wiener Klinische Wochenschrift, 119(9-10), pp. 309-317.

Shkolnikov, V., Leon, D. A., Adamets, S., Andreev, E. and Deev, A. 1998. Educational level and adult mortality in Russia : an analysis of routine data 1979 to 1994. Social Science \& Medicine, 47, pp. 357-369.

Smith, D. W. G. 1993. Human Longevity, New York: Oxford University Press.

Soyka, M. 1999. Alkoholabhängigkeit, Berlin: Springer.

Uhl, A. 2002. Todesfälle durch Substanzkonsum: Wie sinnvoll ist dieses Konzept? Wiener Zeitschrift für Suchtforschung, 25(1/2), pp. 23-32.

Uhl, A., Kopf, N., Springer, A., Eisenbach-Stangl, I., Kobrna, U., Bachmayer, S. and Beiglböck, W. 2001. Handbuch Alkohol - Österreich. Zahlen Daten Fakten Trends 2001. Wien: Bundesministerium für soziale Sicherheit und Generationen.

Uhl, A. and Springer, A. 1996. Studie über den Konsum von Alkohol und psychoaktiven Stoffen in Österreich unter Berücksichtigung problematischer Gebrauchsmuster. Repräsentativerhebung 1993/94. Textband. Wien: Ludwig Boltzmann-Institut für Suchtforschung.

Ulm, K. 1990. A simple method to calculate the confidence interval of a standardized mortality ratio. American Journal of Epidemiology, 131(2), pp. 373-375.

Valkonen, T., Martikainen, P., Jalovaara, M., Koskinen, S., Martelin, T. and Makela, P. I. A. 2000. Changes in socioeconomic inequalities in mortality during an economic boom and recession among middle-aged men and women in Finland. Eur J Public Health, 10(4), pp. 274-280.

Zilker, T. 2004. Sucht. In: Classen, M., Diehl, V. and Kochsiek, K. (Eds.) Innere Medizin. 5 ed. München: Urban \& Fischer. 


\section{VIENNA INSTITUTE OF DEMOGRAPHY}

\section{Working Papers}

Isabella Buber and Henriette Engelhardt, The Relation between Depressive Symptoms and Age among Older Europeans. Findings from SHARE, VID Working Paper $01 / 2008$.

Aparicio Diaz, Belinda, Thomas Fent, Alexia Prskawetz, and Laura Bernardi, Transition to parenthood: The role of social interaction and endogenous networks, VID Working Paper 05/2007.

Ediev, Dalkhat M, On Projecting the Distribution of Private Households by Size, VID Working Paper 04/2007.

Biehl, Kai und Thomas Fent, Vorausschätzungen für die Entwicklung der Gesamtbevölkerung und der Beschäftigung in Österreich bis 2035, VID Working Paper 03/2007.

Feichtinger, Gustav, Maria Winkler-Dworak, Inga Freund, and Alexia Prskawetz, On the Age Dynamics of Learned Societies: Taking the Example of the Austrian Academy of Sciences, VID Working Paper 02/2007.

Winkler-Dworak, Maria and Laurent Toulemon, Gender Differences in the Transition to Adulthood in France: Is There Convergence Over the Recent Period? VID Working Paper 01/2007.

Prskawetz, Alexia, Marija Mamolo, and Henriette Engelhardt, Reconsidering the Relation between Fertility and Key Fertility-Related Demographic Behaviour across Space and Time, VID Working Paper 09/2006.

Mamolo, Marija, Union Formation, Marriage and First Birth: Convergence Across Cohorts in Austria, Hungary, Northern Italy and Slovenia? VID Working Paper 08/2006.

Goujon, Anne and Samir K.C., Past and Future of Human Capital in Southeast Asia: From 1970 to 2030, VID Working Paper 07/2006.

Lyngstad, Torkild H., Does Community Context have Important Bearings on the Divorce Rate? VID Working Paper 06/2006.

Winkler-Dworak, Maria, The Low Mortality of a Learned Society, VID Working Paper 05/2006.

Kim, Jungho and Alexia Prskawetz, External Shocks, Household Consumption and Fertility in Indonesia, VID Working Paper 04/2006.

The Vienna Institute of Demography Working Paper Series receives only limited review. Views or opinions expressed herein are entirely those of the authors. 